Synthesis of Natural

\title{
Synthesis of Epacadostat
}

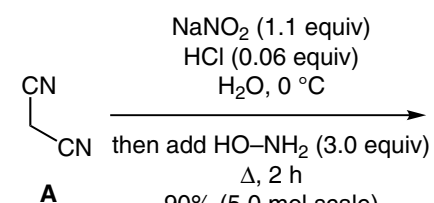

$90 \%(5.0 \mathrm{~mol}$ scale $)$

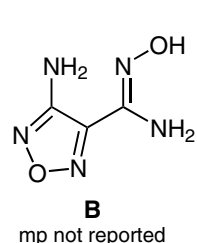

$\mathrm{NaNO}_{2}$ (0.98 equiv)

$\mathrm{HCl}$ (3.0 equiv)

$\mathrm{NaCl}$ (3.0 equiv)

$\mathrm{AcOH}-\mathrm{H}_{2} \mathrm{O}, 0-15^{\circ} \mathrm{C}$

$53 \%(2.95 \mathrm{~mol}$ scale $)$

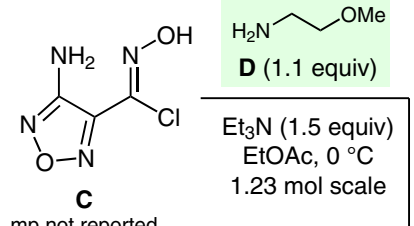

C

mp not reported

tOAc, $0^{\circ} \mathrm{C}$

(

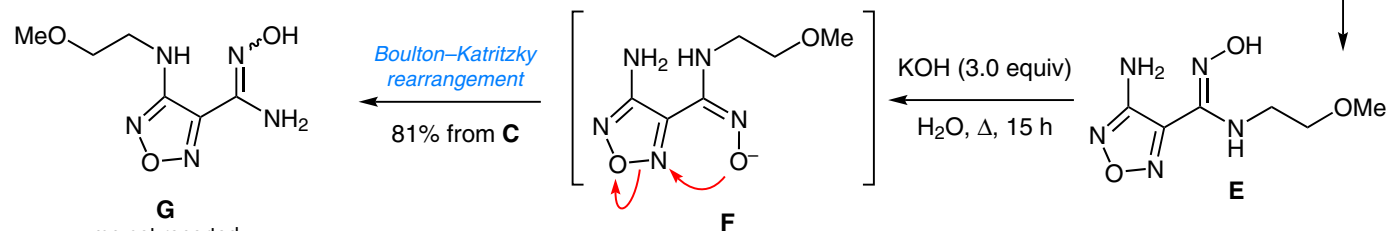

mp not reported

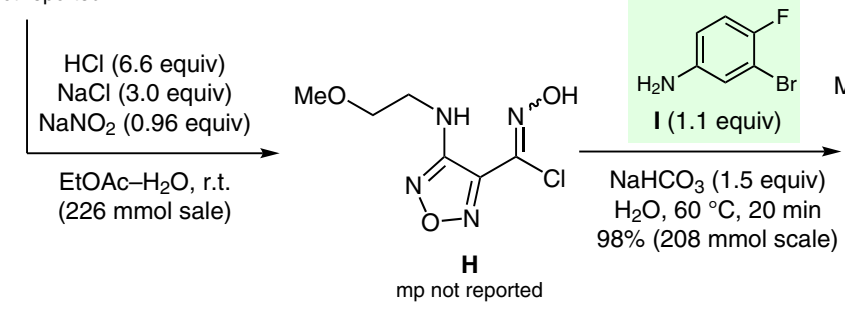<smiles>COCCNc1nonc1C(=NO)Nc1ccc(F)c(Br)c1</smiles>

$\mathrm{CDI}$ (1.5 equiv) EtOAc, $60^{\circ} \mathrm{C}, 20 \mathrm{~min}$ 98\% (204 mmol scale)

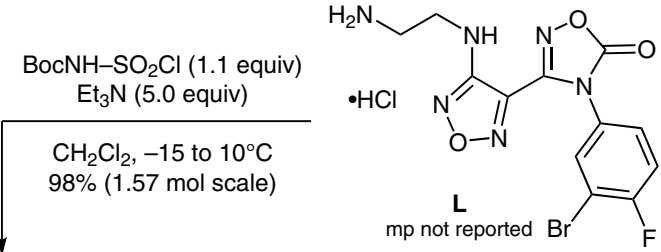

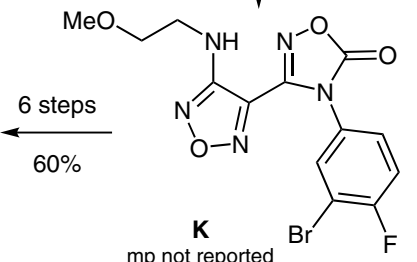

1. TFA- $\mathrm{H}_{2} \mathrm{O}(98: 2)$ $40-50{ }^{\circ} \mathrm{C}, 1 \mathrm{~h}$ $100 \%$ (3.42 mol scale)

2. $\mathrm{NaOH}$ (3.3 equiv)

THF- $\mathrm{H}_{2} \mathrm{O}$, r.t., $3 \mathrm{~h}$

$78 \%$ (2.4 mol scale)<smiles>NS(=O)(=O)NCCNc1nonc1C(=NO)Nc1ccc(F)c(Br)c1</smiles>

\section{Key words}

epacadostat

indoleamine-2,3dioxygenase 1

inhibitors

furazan ring formation

Boulton-Katritzky rearrangement

hydroxyamidines
Significance: Epacadostat (INCB24360) inhibits the immunomodulatory activity of indoleamine2,3-dioxygenase 1, thereby making possible the restoration and/or activation of the immune system in cancer therapy. In combination with pembrolizumab, epacadostat is currently in a phase III clinical trial for the treatment of metastatic melanoma.
Comment: Synthesis of the secondary 3-aminofurazan $\mathbf{G}$ by direct alkylation or reductive amination of the primary 3-amino substituent in $\mathbf{E}$ was low yielding, presumably due to the electron deficiency of the furazan. A general and robust alternate route to secondary amino-furazan $\mathbf{G}$ was accomplished through a Boulton-Katritzky rearrangement of the amidooxime furazan $\mathbf{E}$.

SYNFACTS Contributors: Philip Kocienski

Synfacts 2017, 13(08), 0781 Published online: 18.07.2017

Dol: 10.1055/s-0036-1590682; Reg-No.: K03217SF 